\title{
MAKNA PEPINDHAN MANUSIA DALAM PANYANDRA UPACARA PANGGIH PENGANTIN ADAT JAWA RAGAM SURAKARTA
}

\author{
MEANING OF HUMAN'S PEPINDHAN FROM JAVANESE PANYANDRA WEDDING CEREMONY \\ SURAKARTA'S STYLE
}

\section{Anggyta Aulia Rahma Nardilla}

Program Pascasarjana Universitas Negeri Yogyakarta

Jalan Colombo, Sleman, Daerah Istimewa Yogyakarta 55281, Indonesia

anggytarahma@gmail.com

(Naskah diterima tanggal 18 November 2020, direvisi terakhir tanggal 7 Mei 2021, dan disetujui tanggal 31 Mei 2021)

DOI: https:/ / doi.org/10.26499/wdprw.v49i1.680

\begin{abstract}
This research discusses the types and meanings from human's pepindhan from Javanese panyandra wedding ceremony Surakarta's style in Rejoso Village, Rejoso District, Nganjuk Regency, East Java. The types and the meaning's theory from pepindhan manusia of Javanese panyandra wedding ceremony Surakarta's style in Rejoso Village in this research comes from Padmosoekotjo, Aloysius, and Halley. This qualitative descriptive study using a stylistic approach method. The object of this research are the utterances from Mr. Sujarwo and Mr. Wasito's speech as a famous Master of Ceremony (MC) in Rejoso Village. Data collected through the observations and analyzed by Miles and Huberman's analysis. Data's step analysis from this research through data reduction, presentation data, and verification analysis. Data validity is attempted through triangulation and validity checking. The results of this research indicated that the types of human's pepindhan was found in the Javanese panyandra wedding ceremony Surakarta's style in Rejoso Village, Rejoso District, Nganjuk Regency, East are similes and metaphors. The meaning of human's pepindhan in this research means perfection, luxury, glorious, and beauty from the description of the situation, bridesmaids, conditions, and the good prayers for the household of the bride and groom.
\end{abstract}

Keywords: pepindhan; panyandra; wedding ceremony; ragam Surakarta

\begin{abstract}
Abstrak
Penelitian ini membahas tentang jenis dan makna pepindhan manusia dalam panyandra upacara panggih pengantin adat Jawa ragam Surakarta di Desa Rejoso, Nganjuk, Jawa Timur. Jenis dan makna pepindhan manusia dalam panyandra upacara panggih pengantin adat Jawa ragam Surakarta di Desa Rejoso pada penelitian ini menggunakan teori dari Padmosoekotjo, Aloysius, dan Halley. Penelitian deskriptif kualitatif ini menggunakan metode pendekatan stilistika. Objek kajian dalam penelitian ini ialah tuturan dari pewara terkenal di Desa Rejoso yaitu Bapak Sujarwo dan Bapak Wasito. Data pada penelitian ini dikumpulkan melalui observasi lapangan dan dianalisis menggunakan analisis data Miles dan Huberman. Tahapan analisis data penelitian ini dilakukan dengan tahap analisis reduksi data, penyajian data, dan verifikasi. Keabsahan data pada penelitian ini menggunakan triangulasi data dan pemeriksaan validitas
\end{abstract}


oleh ahli bidang. Hasil dari penelitian ini menunjukan adanya jenis pepindhan manusia yang ditemukan pada panyandra upacara panggih pengantin adat Jawa ragam Surakarta di Desa berupa simile dan metafora. Makna dari pepindhan manusia pada penelitian ini berarti kesempurnan, kemewahan, kesakralan, dan keindahan dari penggambaran keadaan pada resepsi pernikahan, pengiring pengantin, kondisi acara, dan doa yang baik untuk rumah tangga dari pengantin.

Kata-kata Kunci: pepindhan; panyandra; upacara panggih; ragam Surakarta

\section{Pendahuluan}

Bahasa adalah sarana komunikasi berupa simbol bunyi yang dihasilkan alat ucap manusia (Keraf, 1971: 11). Simbol bunyi ini dapat digunakan dalam kegiatan masyarakat. Salah satu bentuk kegiatan masyarakat yang menggunakan bahasa ialah kegiatan upacara panggih ${ }^{1}$ manten ${ }^{2}$ 'pengantin' adat Jawa ragam Surakarta. Upacara panggih pengantin adat Jawa merupakan adalah upacara sakral yang memiliki prosesi yang sudah diatur (Suwarna, 2009: 60). Bahasa yang digunakan pada upacara panggih pengantin adat Jawa ragam Surakarta merupakan salah satu bentuk dari bahasa yang indah. Wujud dari keindahan bahasa dalam upacara panggih pengantin ragam Surakarta ialah panyandra ${ }^{3}$ atau dalam Bahasa Indonesia disebut pencandraan.

Kharimah dan Widayani (2015: 55) berpendapat bahwa panyandra tepengantin dalam ritual pernikahan ini bisa disebut dengan panduan tata cara dalam adat pernikahan Jawa yang menggunakan bahasa Jawa krama inggil atau lebih dikenal dengan bahasa Jawa halus. Panyandra merupakan sususan dari bahasa yang indah yang merupakan ciri khas tuturan pada acara panggih pengantin adat Jawa terkhusus pada upacara panggih pengantin (Suwarna, 2009: 61). Suwarna juga menyampaikan bahwa keterampilan dalam menyampaikan

\footnotetext{
${ }^{1}$ Panggih 'bertemu'(KBBI Daring)

2 Manten 'pengantin' (KBBI, halaman 986)

${ }^{3}$ Panyandra 'penggambaran persitiwa hingga terperinci' (KBBI Daring)
}

panyandra dalam upacara panggih pengantin ini merupakan kecakapan paling tinggi dalam berbicara. Hal ini dikarenakan saat melakukan panyandra itu tidak hanya bertutur, namun juga harus dapat nembang 'menyanyi', mengerti lamba 'irama' dan suasana yang ada.

Panyandra pada upacara panggih pengantin ini dituturkan oleh seorang pranata adicara. Pranata adicara ini memiliki tugas untuk membawakan acara, namun tidak untuk bertindak mengatur dan menjadi pengisi (Suwarna, 2009: 62). Oleh karena itu, pranata adicara dapat dikatakan sebagai seorang Master of Ceremony (MC) atau pewara. Penelitian ini menggunakan objek kajian berupa pewara pengantin terkenal di Desa Rejoso, Nganjuk Jawa Timur yaitu Bapak Sujarwo dan Bapak Wasito. Kedua pewara acara panggih pengantin senior ini menggunakan ragam Surakarta dalam panyandra upacara panggih pengantin di Desa Rejoso- Nganjuk- Jawa Timur. Kedua pewara ini sering dijumpai dalam upacara panggih pengantin bahkan sampai keluar kota. Padahal, kedua pewara yang terkenal ini tidak terlahir dari latar belakang pendidikan yang memiliki pengajaran menjadi pewara, namun kedua pewara ini belajar dari sendiri.

Bapak Wasito ialah pewara paling senior di Desa Rejoso, sedangkan Bapak Sujarwo merupakan murid dari Bapak Wasito yang hanya sekadar belajar di rumah saja. Saat ini, kedua pewara ini juga dipilih karena keduanya memiliki banyak kecakapan yang 
baik dalam menjadi pewara. Kecakapan mereka yaitu memiliki suara yang nyaring, pandai dalam pemilihan diksi yang indah, memiliki panyandra lebih lengkap, dan atraktif. Salah satu unsur keindahan bahasa pada panyandra yang dituturkan oleh pewara ialah pepindhan..

Pepindhan ini dipelajari dalam ilmu stilistika. Stilistika merupakan kajian penggunaan bahasa dalam suatu penuturan, ragam, atau konteks tertentu (Nurgiyantoro, 2015: 3). Hal ini juga sama dengan pendapat dari Sudiyono (2019: 2) yang menjelaskan secara definitif bahwa stilistika adalah ilmu yang berkaitan dengan gaya bahasa. Kegunaan gaya bahasa ini akan memberikan efek tertentu yang berhubungan dengan aspek keindahan. Hal ini yang akan menjadi ciri khas pengarang dalam menyampaikan pikiran, jiwa, dan kepribadian melalui karyanya. Pendapat ini juga sejalan dengan pendapat Padmosoekotjo (1960: 37) yang menyatakan bahwa jenis gaya bahasa dalam Bahasa Jawa sering disebut kasusastran Jawa atau susastra yang terdiri dari wangsalan 'tekateki', pepindhan 'persamaan', sanepa 'sindiran', bebasan', paribasa 'peribahasa', saloka 'pengandaian', parikan 'pantun', panyandra, dasanama 'sinonim', tembung entar', dan tembung saroja ${ }^{6}$.

Teori Padmosoekotjo ini memperjelas bahwa pepindhan salah satu kajian dalam ilmu stilistika. Teori Padmosoekotjo ini memperkuat bahwa pepindhan ini adalah wujud perkataan atau unen-unen yang mencerminkan bahasa pengandaian atau persamaan. Bahasa pengandaian ini terdiri atas pepadan 'persamaan', irib-iriban 'perbandingan', dan emper-emperan 'menyerupai'.

\footnotetext{
${ }^{4}$ Bebasan 'menyerupai' (Kamuslengkap.com 2005)

5 Tembung entar 'kiasan' (Kumparan.com 2021)

${ }^{6}$ Tembung saroja 'rangkap' (Kumparan.com 2021)
}

Indratmo (2015: 17) mengatakan bahwa jenis pepindhan menurut bentuknya itu ada dua, yaitu pepindhan implisit dan pepindhan eksplisit. Menurut ciri-cirinya, pepindhan implisit dapat dikategorikan sebagai metafora, sedangkan pepindhan eksplisit disebut simile. Simile ini memiliki makna eksplisit yang menghadirkan motif pada konstruksinya. Motif ini berupa penanda kata seperti lir, kadya, pendah, akarya, cinandra, dsb yang memiliki arti 'seperti'. Esriaty S. Kendenan (2017: 110) juga mengatakan hal yang sama yaitu simile itu sumber dari teks penulis yang menggunakan penanda kata seperti untuk mengindikasikan adanya unsur simile dan membandingkan kata lain dengan makna yang sama.

Ermi Dyah Kurnia (2016: 284) mengatakan metafora adalah bentuk penyampaian dari suatu objek yang bersifat tidak langsung. Pada dasarnya, pepindhan simile dan pepindhan metafora itu sama-sama menyatakan bentuk penyampaian dari suatu objek yang bersifat tidak langsung, namun yang menjadi pembeda adalah motif yang berupa penanda kata yang hanya dimiliki oleh pepindhan simile saja, sedangkan pepindhan metafora tidak.

Pepindhan yang digunakan dalam penelitian ini dapat dimaknai sebagai bahasa yang mengandung gagasan dari unsur rasa yang bermakna tidak sebenarnya. Halley dalam (Wulandari, 2017: 165) menjelaskan bahwa ada sepuluh kategori metafora yang dapat diklasifikasikan sebagai medan pepindhan yaitu pepindhan keadaan, pepindhan kosmos, pepindhan kekuatan, pepindhan substansi, pepindhan permukaan bumi, pepindhan benda mati, pepindhan gravitasi, pepindhan manusia, pepindhan binatang, dan pepindhan tetuwuhan 'tumbuhan'. Tidak semua medan pepindhan ini dapat ditemukan dalam panyandra upacara panggih pengantin adat Jawa ragam Surakarta di Desa Rejoso. 
Dari semua medan pepindhan menurut teori Halley, pepindhan manusia lebih dominan daripada yang lainnya. Pepindhan atau dapat diartikan sebagai gaya bahasa dalam Bahasa Jawa yang menggambarkan manusia ini banyak ditemukan pada panyandra panggih pengantin. Prosesi yang dilaksanakan dalam upacara panggih pengantin adat Jawa ragam Surakarta di Desa Rejoso erat kaitannya dengan proses kehidupan manusia berupa suasana, pelaksanaan, kegiatan, hingga doa yang disampaikan dalam panyandra masih erat kaitannya dengan kehidupan manusia yang digambarkan dalam rangkaian prosesi upacara panggih pengantin adat Jawa ragam Surakarta di Desa Rejoso.

Upacara panggih pengantin memiliki rangkaian prosesi yang telah diatur (Suwarna 2009). (Suwarna 2009)( Suryani, N. Kairani (2019: 35) memberikan informasi bahwa dalam adat perkawinan Jawa ini memiliki runtutan acara yang harus dijalankan sesuai dengan urutan-urutan prosesinya. Suwarna (2016: 6) menyebutkan prosesi upacara panggih pengantin adat Jawa ragam Surakarta yang di-candra oleh pewara yaitu sebagai berikut:

1. Pengantin putri (PP) masuk

2. Datangnya pengantin kakung ' laki-laki' (PK)

3. Tebusan pisang sanggan 'menerima pinangan $\mathrm{PK}^{\prime}$

4. Kepyokan kembar mayang.

5. PP dan PK berjalan ke papan panggih.

6. Balangan gantal 'lempar sirih'

7. Wiji dadi 'menginjak telur'

8. Ranupada 'PP membasuh kaki PK'

9. Sindur binayang

10. Bobot timbang 'prosesi memangku kedua pengantin'

11. Tanem jero ${ }^{7}$

7 Tanem jero 'kedua pengantin duduk di tempat pengantin' (Wolipop.detik.com n.d.)
12. Kacar-kucur ${ }^{8}$

13. Dhahar klimah ${ }^{9}$

14. Ngunjuk toya wening 'minum air bening'

15. Mapag besan 'menjemput besan'

16. Sungkeman

Objek ini sangat menarik karena peneliti sangat menyukai bidang bahasa. Selain itu, penelitian tentang pepindhan dalam panyandra upacara panggih pengantin adat Jawa ragam Surakarta masih jarang ditemukan. Ada beberapa penelitian tentang panyandra upacara panggih pengantin adat Jawa ragam Surakarta secara luas tidak difokuskan pada satu pepindhan yang mendominasi panyandra upacara panggih pengantin adat Jawa ragam Surakarta. Upacara panggih pengantin adat Jawa ragam Surakarta di Desa juga menarik untuk diteliti karena ada satu prosesi menarik yang berbeda dari upacara panggih yang ada di daerah lain yaitu pelemparan kembang mayang di atap rumah sebagai simbol selesainya acara panggih pengantin.

Pada kenyataanya tidak banyak upacara panggih pengantin adat Jawa ragam Surakarta yang masih selalu menggunakan panyandra. Hal ini dikarenakan menurunnya antusias masyarakat dalam mempelajari bahasa panyandra dalam upacara panggih pengantin adat Jawa ragam Surakarta karena dianggap sulit. Terkhusus lagi, biasanya pepindhan hanya diketahui sebagai unsur bahasa dekoratif saja. Namun Upacara panggih pengantin adat Jawa ragam Surakarta di Desa Rejoso ini selalu menggunakan panyandra.

Pada penelitian ini, pepindhan manusia pada panyandra upacara panggih pengantin

${ }^{8}$ Kacar-kucur 'PK menuangkan isi kantong tikar yang berupa beras kuning, kacang,bunga,dan uang kepada PP sebagai simbol memberi nafkah'(Wolipop.detik.com n.d.)

${ }^{9}$ Dhahar klimah 'makan bersama dengan saling menyuapi satu sama lain sebagai simbol kerukunan' (Wolipop.detik.com n.d.) 
adat Jawa ragam Surakarta di Desa Rejoso memberikan gambaran bahwa panyandra itu tidak hanya untuk diketahui dan dipelajari, tetapi melalui penelitian ini diharapkan pepindhan manusia pada panyandra upacara panggih pengantin adat Jawa ragam Surakarta di Desa Rejoso dapat dijadikan langkah awal dalam melestarikan keindahan bahasa Jawa.

Belajar tentang panyandra ini akan mendukung wawasan tentang eksistensi Bahasa Jawa sebagai profesi yang baik untuk segala kalangan di era modern ini. Hal ini dapat menimbulkan kecintaan masyarakat tentang pentingnya mempelajari, menjaga, dan melestarikan keindahan Bahasa Jawa terutama panyandra upacara panggih pengantin adat Jawa ragam Surakarta di Desa Rejoso yang banyak mengandung unsur keindahan bahasa seperti pepindhan manusia.

\section{Metode}

Penelitian ini menggunakan penelitian deskriptif kualitatif dengan menggunakan metode pendekatan stilistika. Penelitian deskriptif adalah penelitian yang menghasilkan data deskriptif berupa kata dan kalimat dari apa yang sudah ditulis, (Moleong, 2012: 4). Hal ini sesuai dengan penelitian ini karena data yang digunakan dalam penelitian ini adalah data yang berbentuk kalimat yang mengandung pepindhan manusia.

Berdasarkan teori Moleong, peneliti diharapkan tidak hanya sebentar dalam melakukan penelitian agar mendapatkan akurasi data yang baik. Oleh karena itu, penelitian ini dilakukan selama enam minggu dari awal Desember 2019 hingga pertengahan Januari 2020. Jumlah acara upacara panggih pengantin adat Jawa ragam Surakarta di Desa Rejoso yang digunakan adalah sepuluh acara dengan masing-masing pewara adalah lima acara. Oleh karena itu, peneliti selalu ikut serta selama enam minggu dalam setiap acara upacara panggih pengantin adat Jawa ragam Surakarta di Desa Rejoso oleh pewara terpilih.

Sumber data dalam penelitian ini ialah tuturan dari pewara terkenal di di Desa Rejoso yaitu Bapak Sujarwo dan Bapak Wasito. Kedua pewaraini sering sekali dijumpai dalam upacara panggih pengantin adat Jawa ragam Surakarta di Desa Rejoso. Selain itu, kedua pewara senior ini dipilih karena memiliki banyak kecakapan yang baik dalam pewara yaitu panyandra-nya lengkap, suaranya yang nyaring, pemilihan diksi yang indah, atraktif, dan banyak ditemui jenis pepindhan dalam panyandra-nya terutama pepindhan manusia.

Penelitian ini menggunakan data primer yang ditemukan sendiri oleh peneliti di lapangan dengan observasi lapangan, (Moleong, 2012: 157). Beberapa langkah dilakukan dalam menemukan data yaitu observasi lapangan, menyimak, mentranskrip, memberi tanda, dan menerjemahkan katakata dalam untuk lebih memahami maknanya.

Penelitian ini diawali dengan melakukan aktivitas merekam tuturan pewara terpilih. Setelah itu, peneliti mentranskrip hasil rekaman kemudian dibaca berulang-ulang untuk menemukan data akurat tentang pepindhan manusia atau gaya bahasa yang berkaitan dengan penggambaran manusia yang dibutuhan.

Data yang ditemukan ini kemudian diberi tanda, diklasifikasi, dan diidentifikasi berdasarkan formula dan tujuan penelitian yang telah ditentukan (Agustin dan Suwarna, 2019: 91). Selanjutnya, data yang telah diberi tanda ini kemudian ditulis dalam instrumen penelitian berupa kartu data. Kartu data ini digunakan untuk mempermudah dalam menganalisa data yang sudah diklasifikasi sesuai dengan teori pepindhan manusia dari Halley. Instrumen kartu data yang digunakan dalam penelitian ini sebagai berikut: 
Tabel 1

Kartu Data Analisis Jenis Pepindhan Manusia Panyandra Upacara Panggih Pengantin Adat Jawa Ragam Surakarta di Desa Rejoso-Nganjuk.

\begin{tabular}{|c|c|c|c|c|c|}
\hline No. & Teks Panyandra & Panyandra & $\begin{array}{l}\text { Jenis Pe- } \\
\text { pindham } \\
\text { Manungsa }\end{array}$ & Makna & Keterangan \\
\hline 1. & $\begin{array}{l}\text { Soroting netra ri- } \\
\text { sang apindha pra- } \\
\text { meswari mahyaka- } \\
\text { ken raos adhem, } \\
\text { ayem, sarta bisa } \\
\text { hangayoming kang } \\
\text { mahanani tansah } \\
\text { resep dinulu }\end{array}$ & $\begin{array}{l}\text { Penganten } \\
\text { putri }\end{array}$ & Simile & $\begin{array}{l}\text { Lirikan mata pengan- } \\
\text { tin putrid seperti ratu } \\
\text { yang memenangkan } \\
\text { jiwa dan mengayomi } \\
\text { siapapun yang meli- } \\
\text { hatnya }\end{array}$ & $\begin{array}{l}\text { Acara panggih pengan- } \\
\text { tin Mas Walid dan } \\
\text { Mbak Yunita oleh Ba- } \\
\text { pak Sujarwo. }\end{array}$ \\
\hline
\end{tabular}

Data yang ditemukan kemudian ditulis pada kartu data. Selanjutnya, akan dilakukan triangulasi data untuk membandingkan data satu dengan data yang lain, yang dilakukan secara fokus untuk menemukan kesamaan dan temuan data baru dalam setiap transkrip rekaman dari setiap panyandra di tuturan pewara Bapak Sujarwo Bapak Wasito hingga menemukan data jenuh.

Data jenuh adalah data yang memiliki kesamaan dengan data yang sebelumnya telah ditemukan. Lamanya pengambilan data dalam penelitian ini juga dimaksudkan untuk menemukan data jenuh dalam periode yang telah ditentukan. Data jenuh ini dapat diketahui dari ditemukannya banyak kesamaan data yang dapat dijumpai dalam penelitian yang dilaksanakan. Kesamaan data ini akan selalu berulang dan sama seperti hasil data penelitian sebelumnya. Data jenuh ini dimaksudkan untuk menciptakan kriteria kepercayaan dalam penelitian kualitatif sesuai dengan teori (Moleong, 2012: 325). Data jenuh ini kemudian digunakan untuk menemukan keabsahan data.

Keabsahan data digunakan untuk mengumpulkan data yang dapat dipertanggungjawabkan, (Moleong, 2012: 320). Setelah data ditulis dalam instrumen penelitian kemudian data akan dianalisa. Analisis data dalam penelitian ini menggunakan analisis data kualitatif dari Miles dan Huberman. Analisis data dari Miles dan Huberman ini dilaksanakan melalui tahapan pengumpulan data, penyajian data, reduksi data, dan dan verifikasi data.

Kegiatan selanjutnya adalah pemeriksaan sejawat dengan diskusi dan konsultasi dengan ahli bidang. Ke-valid-an hasil penelitian dapat dilakukan dengan membaca dan menganalisa secara teliti dan cermat. Peneliti membaca hasil temuan data pepindhan manusia dalam panyandra upacara panggih pengantin adat Jawa ragam Surakarta di Desa Rejoso berulang kali. Di sisi lain, peneliti juga mengadakan konsultasi dengan dosen pembimbing untuk mendapatkan kritik saran serta masukan dari kepastian data yang ditemukan supaya benar-benar sah dan valid. Kegiatan ini dipastikan untuk mendapatkan data yang valid tidak hanya dari perspektif peneliti tapi juga atas dasar persetujuan temuan data berdasarkan teori yang digunakan supaya hasilnya akan baik, (Moleong 2012). 


\section{Hasil dan Pembahasan}

Penelitian pepindhan manusia dalam panyandra upacara panggih pengantin adat Jawa ragam Surakarta di Desa Rejoso memiliki jenis dan makna. Hasil penelitian yang didapat dari subjek penelitian tuturan dari pewara terkenal di di Desa Rejoso yaitu Bapak Sujarwo Bapak Wasito yang ditranskrip menggambarkan banyak dijumpai pepindhan manusia dalam panyandra upacara panggih pengantin adat Jawa ragam Surakarta di Desa di Desa Rejoso. Data yang telah ditranskrip ini kemudian diterjemahkan dan dianalisa jenis dan maknanya. Selain itu, sebenarnya ada beberapa improvisasi dari kedua pewara untuk mengisi acara, tetapi tidak ditranskrip karena tidak berhubungan dengan panyandra panyandra.

Jenis pepindhan panyandra upacara panggih pengantin adat Jawa ragam Surakarta di di Desa Rejoso yang ditemukan dalam penelitian ini disajikan dalam bentuk tabel sebagai berikut:

Tabel 2

Jenis Pepindhan Panyandra Upacara Panggih Pengantin Adat Jawa Ragam Surakarta di Desa Rejoso oleh Bapak Sujarwo dan Bapak Warsito

\begin{tabular}{cccccccccc}
\hline Pepindhan & \multicolumn{3}{c}{ Kahanan } & \multicolumn{1}{c}{ Aran } & \multirow{2}{*}{ Jumlah } \\
\cline { 2 - 9 } & PKH & PKK & PKO & PP & PB & PM & PH & PT & \\
\hline Implisit & 2 & 4 & - & - & 1 & 2 & 5 & 2 & 16 \\
$\begin{array}{c}\text { (Metafora) } \\
\text { Eksplisit }\end{array}$ & 5 & 1 & 4 & 1 & 8 & 8 & 2 & 5 & 35 \\
$\begin{array}{c}\text { (Simile) } \\
\text { Jumlah }\end{array}$ & 7 & 5 & 4 & 1 & 9 & 10 & 7 & 7 & 51 \\
\hline
\end{tabular}

\section{Keterangan:}

a. Pepindhan Keadaan (PKH)

b. Pepindhan Kekuatan (PKK)

c. Pepindhan Kosmos (PKO)

d. Pepindhan Permukaan Bumi (PP) e. Pepindhan Benda Mati (PB)

f. Pepindhan Binatang (PH)

g. Pepindhan Manusia (PM)

h. Pepindhan Tumbuhan (PT) 
Berdasarkan data tabel 2 di atas, dapat disimpulkan bahwa pepindhan manusia memang lebih sering ditemukan dalam dalam panyandra upacara panggih pengantin adat Jawa ragam Surakarta di di Desa Rejoso. Jenis pepindhan manusia yang ditemukan dalam penelitian ini ada dua yaitu pepindhan metafora dan simile. Jumlah pepindhan manusia dalam penelitian ini lebih banyak ditemukan karena banyak hal yang di-candra banyak berhubungan dengan kehidupan manusia sebagai makhluk yang mendekati kesempurnaan.

Selain itu, semua yang dekat dengan kehidupan manusia juga termasuk di dalamnya seperti doa baik untuk kelangsungan hidup manusia juga menambah pepindhan manusia menjadi lebih dominan dibandingkan dengan pepindhan lainnya. Pepindhan manusia sering digunakan karena sering juga dikaitkan dengan tokoh terkenal yang memiliki kepribadian yang baik dan memiliki nilai-nilai budi luhur sebagai contoh yang baik

Berdasarkan data penelitian, jumlah pepindhan manusia simile lebih banyak dari metafora. Hal ini dapat dilihat dari banyaknya pepindhan manusia yang memilik kata penanda sebelum menyebutkan pepindhan. Bentuk pepindhan simile pada penelitian ini dapat dilihat dari kata-kata penanda berupa "lir, kadya, pendah, akarya, cinandra, dsb".

Jumlah pepindhan manusia lebih banyak dari pepindhan yang lain pada panyandra upacara panggih pengantin adat Jawa ragam Surakarta di Desa Rejoso. Hal ini berkaitan dengan semua prosesi yang dilakukan dalam upacara panggih pengantin adat Jawa ragam Surakarta di Desa Rejoso banyak yang berhubungan dengan rangkaian kehidupan manusia seperti barang-barang yan digunakan, aktivitas, dan pengambaran kehidupan manusia dalam cerita masa lalu seperti cerita wayang. Semuanya sangat erat kaitannya dengan kehidupan manusia. Selain itu, ada juga wujud doa yang disampaikan untuk pengantin dalam panyandra upacara panggih pengantin adat Jawa ragam Surakarta di Desa Rejoso. Pengantin didoakan agar sejahtera kehidupannya dan digambarkan seperti tokoh terkenal dalam pewayangan yang memiliki watak atau cerita hidup yang baik sebagai cerminan contoh watak dan kehidupan baik dari manusia.

Pembahasan dari temuan data penelitian pepindhan manusia dalam panyandra upacara panggih pengantin adat Jawa ragam Surakarta di Desa Rejoso berupa simile dan metafora sebagai berikut:

1. Punapa kang ganjil candraning risang penganten putri Rara Ayu Dewi Yunita Eka Sari dhasar kenya badhe hangrungkebi jejering maneka ingkang utami.

'Pengantin putri Rara Ayu Dewi Yunita Eka Sari sedang berusaha untuk memenuhi sunnah Rasul untuk berumah tangga saat ini.'

Data (1) ini ialah wujud pepindhan manusia metafora. Data ini ditemukan dalam panyandra Bapak Sujarwo pada acara panggih pengantin Mas Walid dan Mbak Yunita. Data (1) ini memiliki makna untuk menggambarkan wujud upaya bakti dari tepengantin putri untuk memenuhi sunnah rasul untuk berumah tangga dengan orang yang dicintai.

2. Soroting netra risang apindha prameswari mahyakaken raos adhem, ayem, sarta bisa hangayomi ingkang mahanani tansah resep dinulu.

'Lirikan mata pengantin putri seperti istri raja yang menenangkan jiwa dan dapat mengayomi siapapun yang mengenalnya.'

Data (2) ialah wujud pepindhan manusia simile. Data ini ditemukan dalam panyandra Bapak Sujarwo pada acara panggih pengantin Mas Walid dan Mbak Yunita yang memiliki kata penanda apindha 'seperti'. Data (2) memiliki makna untuk mengambarkan indahnya mata dari pengantin putri seperti 
pandangan ratu yang mengayomi hati rakyatnya.

\section{Priya pideksa kalih cacahipun ing sapengkering penganten punika wnang den sebut Mangga- laYudha kadi satriya prajurit kang gagah prakosa. \\ 'Pria kembar yang jumlahnya dua disebelah pengantin pria itu disebut Manggala Yudha seperti prajurit yang gagah perkasa.'}

Data (3) ialah wujud pepindhan manusia simile. Data ini ditemukan dalam panyandra Bapak Sujarwo pada acara panggih pengantin Mas Walid dan Mbak Yunita yang memiliki kata penanda kadi 'seperti'. Data (2) memiliki makna untuk kesempurnaan dari pengantin pria yang diibaratkan satriya prajurit yang gagah perkasa.

4. Mila kelamun pinetha ing wardaya candrane kadinarendra ingkang arsa tedhak siniwaka. 'Oleh karena itu, pesona pengantin laki-laki ini diibaratkan sepeti raja yang sedang duduk di tahtanya.'

Data (4) ini ialah wujud pepindhan manusia simile. Data ini ditemukan dalam panyandra Bapak Sujarwo pada acara panggih pengantin Mas Walid dan Mbak Yunita yang memiliki kata penanda kadi. Data (4) ini memiliki makna untuk menggambarkan keagungan pengantin pria seperti raja di keraton.

5. Upacara kirabing penganten saya tambah adi kawuryan karan asri penganten wus ngagem busana kasatriyan candrane kadya Raden Bagus Dhanang Sutawijaya atmajane Ki Pemanahan, hanganthi garwanira Dewi Samangkin, putra putrinipun Sunan Bagus Prawaing Kalinyamat.

'Upacara kirab pengantin semakin agung karena pengantin sudah memakai busana ksatriyan, pancarannya seperti Raden Bagus Dhanang Sutawijaya anaknya Ki Pemanahan yang menggandeng istrinya Dewi Samangkin anaknya Sunan Bagus Purwa dari Kalinyamat.'
Data (5) ini ialah wujud pepindhan manusia simile. Data ini ditemukan dalam panyandra Bapak Sujarwo pada acara panggih pengantin Mas Walid dan Mbak Yunita yang memiliki kata penanda kadya 'seperti'. Data (5) ini memiliki makna untuk menggambarkan wujud kirab tepengantin yang mewah seperti kirab raja yang dihargai dan dicintai rakyat.

6. Lulus raharja panggihipun risang panganten sarimbit badhe kalenggahaken ing sasana rinengga pindha narendra ari sajuga.

'Setelah bertemunya kedua pengantin, selanjutnya kedua pengantin akan dipersilakan untuk duduk di tempat yang telah disediakan dan dihias indah seperti singgah sana raja.'

Data (6) ini ialah wujud pepindhan manusia simile. Data ini ditemukan dalam panyandra Bapak Sujarwo pada adicara panggih pengantin Mas Walid dan Mbak Yunita yang memiliki kata penanda rinengga 'disebut'. Data (6) ini memiliki makna berupa doa untuk kedua pengantin agar selalu dihargai dan dihormati oleh banyak orang seperti seorang raja dan ratu sebagai pemimpin.

7. Putri dhomas ingkang minangkan para warara, kawuryan kaya putri perdikan saking bawah jagad Banyubiru.

'Putri dhomas yang bertugas mengiringi terlihat seperti putri perdikan dari bumi Banyu biru.'

Data (7) ini ialah wujud pepindhan manusia simile. Data ini ditemukan dalam panyandra Bapak Sujarwo pada acara panggih pengantin Mas Dhawarasati dan Mbak Cici yang memiliki kata penanda kaya 'seperti'. Data (7) ini memiliki makna untuk menggambarkan dhomas yang diibaratkan seperti putri kraton jagad banyu biru yang sangat cantik .

8. Nulya penganten kalih kalenggahaken ing dampar rinengga, tandha yekti bilih penganten sarimbit 
sampun kawisuda wimbane raja sedina ratu sedalu.

'Oleh karena itu, kedua pengantin ini diminta untuk duduk di singah sana tahta yang menandakan bahwa kedua pengantin sudah diresmikan sebagai raja dan satu semalam.'

Data (8) ini ialah wujud pepindhan manusia metafora. Data ini ditemukan dalam panyandra Bapak Sujarwo pada acara panggih pengantin Mas Dhawarasati dan Mbak Cici. Data (8) ini memiliki makna saat pengantin melaksanakan semua prosesi panggih pengantin ini diibaraktkan seperti menjadi raja dan ratu semalam.

9. Dene manggalayudha cinandra Suwandageni, atmajane Ki Demang Sangkal putung miwah Sang Agung Sedayu, putrane Ki Sadewa ingkah kalih-kalihipun saking tlatah Jatianom.

'Sedangkan Manggalayuda diibaratkan seperti Suwandageni, anaknya Ki Demang Sangkal putung beserta Sang Agung Sedayu, anak dari Ki Sadewa, mereka berdua dari daerah Jatianom.'

Data (9) ini ialah wujud pepindhan manusia simile. Data ini ditemukan dalam panyandra Bapak Wasito pada acara panggih pengantin Mas Fudin dan Mbak yang memiliki kata penanda cinandra 'disebut'. Data (9) ini memiliki makna untuk menggambarkan Manggalayudha yang diibaratkan seperti seorang Suwandageni yang gagah dari Jatianom.

10. Gantal dumadi saking suruh lininthing sumbut yen dinulu hamengku wedi sinandi, nadyan kang saboga jejering priya ingkang sawiji pawestri.

'Gantal dibuat dari daun sirih yang digulung sepadan dengan karisma laki-laki meskipun sebagai laki-laki harus tetap bersanding dengan perempuan agar saling melengkapi.'

Data (10) ini ialah wujud pepindhan manusia metafora. Data ini ditemukan dalam panyandra
Bapak Wasito pada acara panggih pengantin Mas Yuda dan Mbak Ziana. Data (10) ini memiliki makna untuk menggambarkan gantal 'gulungan dari daun sirih' yang digulung saat prosesi balangan gantal merupakan simbol bersatunya pria dan wanita untuk saling mencintai.

Pepindhan manusia yang berupa simile banyak ditemukan dalam penelitian pepindhan panyandra upacara panggih pengantin adat Jawa ragam Surakarta di Desa Rejoso. Pepindhan manusia simile yang memiliki penanda kata akan mempermudah pembaca dan pendengar untuk mengetahui adanya unsur pepindhan dalam panyandra upacara panggih pengantin adat Jawa ragam Surakarta di Desa Rejoso.

Pepindhan manusia dalam penelitian ini memiliki makna untuk menggambarkan kesempurnan, kemewahan, kesakralan, dan keindahan aspek dalam pernikahan yaitu busana, tempat, keadaan, pelaksanaan hingga doa yang baik untuk kebaikan, kebahagiaan, dan keberkahan untuk kedua pengantin. Pepindhan manusia juga dalam penelitian ini juga berisi tentang harapan agar dipenuhi dengan keberkahan dan kebaikan dalam hidup bersama.

\section{Penutup}

Pepindhan manusia banyak ditemukan dalam upacara panggih pengantin ragam Surakarta di Desa Rejoso. Pepindhan manusia yang menggambarkan manusia ini banyak ditemukan karena upacara panggih pengantin ragam Surakarta banyak berhubungan dengan aktifitas dan deskripsi manusia. Berdasarkan hasil dan pembahasan, ditemukan sepuluh data pepindhan manusia yang memiliki jenis simile dan metafora.

Makna dari pepindhan manusia yaitu menggambarkan bentuk kesempurnaan, kemewahan, kesakralan, dan keindahan aspek dalam pernikahan. Hal itu tercermin 
pada busana, tempat, keadaan, pelaksanaan hingga doa yang baik untuk kebaikan, kebahagiaan, dan keberkahan untuk kedua pengantin. Selain itu, pepindhan manusia juga dalam penelitian ini juga berisi tentang harapan agar dipenuhi dengan keberkahan dan kebaikan dalam hidup bersama.

\section{Daftar Pustaka}

Agustin, Eka Francisca Fitri, and Suwarna Suwarna. 2019. "Mimicry and Radical Resistance in Novel Saman." Hlm. 9094 in Mimicry and Radical Resistance in Novel Saman. Vol. 257. Yogyakarta. https://doi.org/10.2991/icollite18.2019.19

Ermi Dyah Kurnia. 2016. "Metafora Binatang dalam Peribahasa Jawa." hlm. 283-87 in Metafora Binatang dalam Peribahasa Jawa. Semarang: International Seminar Prasasasti III : Current Research in Linguistic.

Esriaty S. Kendenan. 2017. “Simile \& Metaphor in Translation: A Study on Students' Translation of Amy Tan'S 'Two Kinds' Short Story." Language Circle: Journal of Language and Literature 10(2):107-16.

Indratmo, Aloysius. 2015. “Pepindhan Dan Sanepa: Cara Bertutur Yang Tidak Biasa." hlm. 107-13 in Prosding Seminar Nasional Prasasti II "kajian Pragmatik dalam Berbagai Bidang". Vol. 2. Semarang: Prosding Seminar Nasional Prasasti II "kajian Pragmatik dalam Berbagai Bidang.

Kamuslengkap.com. 2005.

"Screenshot_2021-01-01-06-27-37213_com."

KBBI. 2016a. “KBBI.”
KBBI. 2016b. “Screenshot_2021-04-15-12-0528-137_cn." 986.

Keraf, Gorys. 1971. Komposisi: Sebuah Pengantar Kemahiran Bahasa. Ende: Nusa Indah.

Kharimah, Aminatun, Rizka Widayani, dan Universitas Airlangga Surabaya. 2015. "Panyandra Temanten dalam Pernikahan Adat Jawa sebagai Aktualisasi Pemertahanan Bahasa Ibu." Jurnal Tutur 1(1):55-64.

Kumparan.com. 2021. "Screenshot_2021-0204-18-58-32-984_com.” Kumparan.Com.

Moleong, Lexy J. 2012. Moleong, Lexy J.2012. Metodologi Penelitian Kualitatif. Bandung: PT Remaja Rosdakarya. Bandung: PT Remaja Rosdakarya.

Nurgiyantoro, Burhan. 2015. "Stilistika Kultural." Widyaparwa 43(1):1-13. https://doi.org/10.21831/ltr.v13i2.257 5

Padmosoekotjo. $1960 . \quad$ Ngengrengan Kasusastran Jawa I. Yogyakarta: Hien Hoo SIng.

Sudiyono. 2019. "Stilistika dalam Novel Para Priyayi Karya Umar Kayam." Jurnal Pendidikan dan Pembelajaran Khatulistiwa 8(10):1--9. https:/ / doi.org/10.33603/jt.v1i1.1089

Suryani, N. kairani, R. Aprianti dkk. 2019. "Nilai Pendidikan Karakter pada Upacara Panggih Temanten Pada Masyarakat Jawa Silaut." Jurnal Perspektif: Jurnal Kajian Sosiologi dan Pendidikan 2(1):34--40. https:/ / doi.org/10.24036/perspektif.v 2i1.61 
Suwarna. 2009. Bahasa Pewara. Yogyakarta: Wulandari, Ari. 2017. “Kearifan Lokal Pustaka Pelajar. Orang Jawa dalam Metafora Novel Para Priyayi Karya Umar Kayam."

Suwarna. 2016. “Upacara Penganten Sala." Besmart UNY 1--33. SASDAYA, Gadjah Mada Journal of Humanities 1(2):164--183.

Wolipop.detik.com. n.d. "Screenshot_2020https:// doi.org/10.22146/sasdayajour nal.27779 12-10-22-13-07-219_com." 